\title{
THEMATIC PROGRESSION AND ITS TYPES IN ENGLISH LITERARY AND LEGISLATIVE TEXTS
}

\author{
Marina Kizil \\ Dnipropetrovsk State University of Internal Affairs, Dnipro, Ukraine \\ marina2kizil@gmail.com \\ Elina Kushch \\ National University "Zaporiz'ka Politekhnika” \\ elina.e2016@gmail.com
}

\begin{abstract}
The focus of the article is Thematic Progression as a text and a genre forming phenomenon. Thematic Progression contributes to the cohesive development of any text, the distribution of given and new information of which needs to follow certain patterns. Thematic progression patterns deal with the set of meaningful sense groups which constitute a coherent text. Basic thematic progression patterns are: simple linear thematic progression, thematic progression with a continuous (constant) Theme, thematic progression with derived Themes and thematic progression with a split Rheme. They are peculiar to many languages. However, texts of different genres and the same language exhibit different patterns of Thematic Progression. This indicates that Thematic Progression, its patterns and their varieties are genre specific. To prove this, the article dwells on the Theme progression patterns and peculiar features of their Theme-Rheme organisation in texts of literary and legislative genres. While linear-constant thematic progression patterning is typical of a literary text, a legislative text is mainly based on the constant-linear thematic progression pattern. Constantlinear thematic progression patterning in the legislative text contributes to its informativeness, argumentativeness, unambiguity, and detailed specification of the given information. In comparison with the legislative text, the literary text has a variety of thematic progression patterns made of linear thematic progression, derived thematic progression and elliptical progression types. Regular linear-constant thematic progression patterning employed in the literary text helps to unfold textual information successively that contributes to its coherence and more effective perception.
\end{abstract}

Keywords: genre; legislative; literary; pattern; text; Thematic Progression; Theme-Rheme organisation.

\section{Introduction}

Linguists have always striven to understand the nature of language and the principles of its functioning. Attempts to explain how language functions developed in two directions: formal and functional. The Prague School of Linguistics as a representative of the functional approach to language study, developed the theory of Functional Sentence Perspective (FSP) as "it follows from the recognition of the instrumental character of language and is manifested in the lasting interest in the problems of meaning, in the "linguistics of parole", in stylistics, in the analysis of text, as well as in practical applications" (Daneš, 1989). The functional approach proved to be a real incentive in sentence studies when the sentence is analysed in the context and analysis goes beyond the sentence boundaries. The theory of Functional Sentence Perspective has evolved and expanded into a number of related concepts, like the Communicative Dynamism, the Pragmatic Perspective, and the Thematic Progression.

Although a considerable amount of theoretical works has been published relating to Functional Sentence Perspective (Daneš, 1989; Fibras, 1992; Dušková, 2015; Drápela, 2015), much fewer publications dealing with the analysis of Thematic Progression, understood as "the exchange of information between successive Theme and Rheme pairings in a text" (Abed, 2015, p. 77), seem to be available.

Different constructive ways of Theme and Rheme are called thematic progression patterns as they are Theme and Rheme extension patterns. A thematic progression pattern appears when a set of meaningful sense groups constitute a coherent text and some connections may be used between Theme and Rheme of a clause. Different texts exhibit different patterns of Thematic Progression.

Despite the commonly accepted fact that thematic progression patterns are genre specific, i.e. they are more characteristic of texts of one genre rather than another (Dubois, 1987; Nwogu \& Bloor, 1991; Ghadessy, 1995; Abdol \& Hamed, 2014; Abed, 2015; Fang \& Li, 2015), the contrastive analysis of thematic progression patterns peculiar of texts of totally dissimilar genres is still lacking its theoretical consideration. Only texts of the same genre (Rahmawati \& Kurniawan, 2015), sub-genres (Ghadessy, 1995; Abdol \& Hamed, 2014) or closely related genres (Nwogu \& Bloor, 1991) have been objects of scholarly interest. However, analysis of thematic progression patterns of the texts of totally different genres contributes to further understanding of their pragmatic value, functionally stipulated difference and specificity at the level 
of semantic and syntactic structures. Such an analysis provides a functional explanation of information ordering of texts of different genres.

\section{Data and Methodology}

The present research is restricted to the analysis of thematic progression patterns of two types of text literary (fiction) and legislative, collected from the following sources: the novel "Tender is the Night" (Fitzgerald, 1996) and "The Treaty on European Union" (2010), "The Treaty on the Functioning of the European Union" (2010) belonging to the category of legislative texts. The scope of the research material is 1472 clauses, 736 per text type.

The paper follows the theoretically deduced and linguistically acknowledged anthropocentric approach postulating the verbally marked presence of a human being in any text. Distribution of texts into genres goes hand in hand with pragmatically required and linguo-stylistically shaped pieces of utterances constructed by one person/s and addressed to another/s. This idea determines and influences the choice of verbal means used by the authors of both text types and helps issue a hypothesis that Thematic Progression and its types are arbitrary text constructs originating from 1) stylistic relevance - genre, 2) pragmatic value of a text.

The study also grounds on methodological principles of systemic functional linguistics (Maton, Martin \& Matrrugilio, 2016) and systemic functional grammar (Halliday \& Hasan, 1976; Halliday, 1995), which reveal the instrumental character of a language, its structures and units. It is conducted through utilising qualitative and quantitative analysis of the data. The qualitative functional analysis of the texts is carried out with the focus on the thematic-rhematic sequences in text sentences to establish thematic progression patterns. The method of contrastive analysis is employed to highlight both differences and similarities in the use of thematic progression patterns in English literary and legislative texts. Finally, the calculation of the relative frequency of occurrence of thematic progression patterns in two types of texts is carried out, which suggests the characteristic features of ordering ideas in two different genres of English texts.

\section{Results and Discussion}

The present paper focuses on Daneš classification of thematic progression patterns. The scholar differentiated their four basic types: simple linear thematic progression, thematic progression with a continuous (constant) Theme, thematic progression with derived Themes and thematic progression with a split Rheme (Daneš, 1974, pp. 108-109). The pattern of simple linear thematic progression is considered to be most elementary, as an item from the rheme of the first clause becomes the Theme of the subsequent clause in this pattern. In continuous (constant) Theme pattern, the Theme of the first clause is also selected as the Theme of the subsequent clause. Themes are derived from a hypertheme or from the same overriding Theme in the pattern of thematic progression with derived Themes.

In the pattern of thematic progression with a split rheme, a rheme may include a number of different pieces of information, each of which may be taken up as the Theme in a number of subsequent clauses. This pattern shows that the Rheme is explicitly or implicitly doubled $\left(\mathrm{R}^{\prime}+\mathrm{R}^{\prime \prime}\right)$ or multiple $\left(\mathrm{R}^{\prime}+\mathrm{R}^{\prime \prime}+\mathrm{R}^{\prime \prime \prime}+\ldots\right)$; these partial progressions may be of one type only or they may represent a combination of different types, without necessarily having a parallel structure. This type of progression is called a "combination of a higher order, the most important frame" (Danes, 1988, p. 194). Moreover, Thematic Progression contains such a pattern as a split Theme. It develops when a Theme contains more than one idea and these ideas are developed in different clauses. So, Thematic Progression may be employed in various combinations, which reveal a certain regular pattern. There are a lot of thematic progression combinations in different texts, i.e. linear - constant progression, constant - linear progression, elliptical progression, and many others. Abdol and Hamed point out that the combinations of simple linear thematic progression and constant thematic progression are the most typical of English texts in general (Abdol \& Hamet, 2014, p. 44). Constant thematic progressions occur more frequently in English argumentative texts while linear thematic progression patterning is typical of English narrative texts (Enkvist, 1974).

Thematic progression patterns differ when applied to various literary genres. According to Fang and $\mathrm{Li}$, “... in a narrative discourse, each sentence puts the characters, time, and places as the starting point, so it tends to adopt more parallel progression. In another words, we use different patterns of thematic progression in different literary genres" (Fang \& Li, 2015, p. 6). Tan \& Sun found features of Theme structure for literary genres of exposition character: linear and derived thematic progression appear 26,7\% whereas constant Themes appear 20\% (Tan \& Sun, 2010, p. 143).

The literary text under analysis exhibits a variety of different thematic progression types. The following is a typical example of constant thematic progression, where the Theme of the previous clause is repeated as the Theme in the following one: 
(1) With half an hour to wait for her train Rosemary sat down in the Café des Alliés on the Croisette, where the trees made a green twilight over the tables and an orchestra wooed an imaginary public of cosmopolites with the Nice Carnival Song and last year's American tune. She had bought Le Temps and The Saturday Evening Post for her mother, and as she drank her citronade she opened the latter at the memoirs of a Russian princess, finding the dim conventions of the nineties realer and nearer than the headlines of the French paper (Fitzgerald, 1996, p. 22).

T1 (...Rosemary) R1 (the Café des Alliés...)

T1 (She) R2 (Le Temps ...)

T1 (... she) R3 (the latter ...).

Example 2 demonstrates the model of simple linear thematic progression, in which the given information in each sentence topic refers anaphorically to the new information in the last occurring comment:

(2) Out there the hot light clipped close her shadow and she retreated (Fitzgerald, 1996, p. 7).

T1 (Out there the hot light) R1 (her shadow)

T2 (and she) R2 (retreated).

The following is a typical instance of derived thematic progression:

(3) Nearest her, on the other side, a young woman lay under a roof of umbrellas making out a list of things from a book open on the sand. Her bathing suit was pulled off her shoulders and her back, a ruddy, orange brown, set off by a string of creamy pearls, shone in the sun. Her face was hard and lovely and pitiful. Her eyes met Rosemary's. Beyond her was a fine man in a jockey cap and redstriped tights (Fitzgerald, 1996, p. 9).

T1(... a young woman) R1 (lay under ....)

T1 (Her bathing suit) R2 (was pulled off...)

T1 (...her back...) R3 (shone...)

T1 (Her face) R4 (was hard...)

T1 (Her eyes) R5 (met...)

T1 (Beyond her) R6 (was...).

The analysis of the text reveals that linear and constant thematic progressions are found in its descriptions, explanations and conversations. Derived thematic progressions are used by the author in explanation and description of places and characters.

The analysis of the thematic-rhematic sequences in the literary text shows that linear-constant thematic progression patterning predominates in it $(42,9 \%)$. The following examples illustrate the usage of these combinations:

(4) He desired her and, so far as her virginal emotions went, she contemplated surrender with equanimity. Yet she knew she would forget him half an hour after she left him-like an actor kissed in a picture (Fitzgerald, 1996, p. 36).

T1 (He) R1 (her...)

T2 (she) R2 (a surrender...)

T2 (... she) R3 (him...).

(5) The undertone of his words repelled her and she withdrew her adoration for the Divers from the profanity of his bitterness. She was glad he was not next to her at dinner and she was still thinking of his words 'especially her' as they moved towards the table in the garden (Fitzgerald, 1996, p. 46).

T1 (... his words) R1 (her...)

T2 ( and she) R2 (her addoration...)

T2 (She) R3 (he...)

T2 (and she) R4 (his words...).

The second pattern of Thematic Progression used in the literary text is elliptical (32,3\%). This type of thematic progression combination is usually blocked by the omission of the subject of the following sentence as it is illustrated in Examples 6-7:

(6) Then he shouldered his last piece of junk and went up to his car, and Rosemary came out of the water, shook out her peignoir and walked up to the hotel (Fitzgerald, 1996, p. 18).

T1 (Then he) R1 (shouldered his last piece of junk)

T2 (he) R2 (went up to his car)

(7) Rosemary stopped in the lobby and spoke to Gausse père about trains (Fitzgerald, 1996, p. 21).

T1 (Rosemary) R1 (stopped in the lobby)

$\mathrm{T} 2$ (Rosemary) R2 (spoke to Gausse père about trains). 
The third thematic progression combination in the novel under analysis is constant-linear progression $(24,8 \%)$ starting with the constant thematic progression and shifting to the linear thematic progression. This pattern is rendered more coherent and cohesive. Any of thematic progression types, regular or gapped, may be repeated several times in a sequence corresponding to a train of thought in the text. The following extracts show clearly how these connecting relationships occur in the novel:

(8) 'It's not a bad time,' said Dick Diver. He looked at her and for a moment she lived in the bright blue worlds of his eyes, eagerly and confidently (Fitzgerald, 1996, p. 17).

T1 (said Dick Diver) R1 ('It's not a bad time,')

T1 ( He) R2 (looked at her)

T2 (...she) R3 (lived in the bright blue words ...).


the intention of confiding in him, but at her first mention of Dick a hard-boiled sparkle in his eyes gave her to understand that he refused the fatherly office. In turn she was equally firm when he tried to monopolize her hand (Fitzgerald, 1996, p. 47).

T1 (She) R1 (Luis Campion and Brady)

T1 ( ... she) R2 (to Brady...)

T2 (...a hard-boiled sparkle in his eyes) R3 (gave her to understand)

T1 (... she) R4 (her hand).

The following table indicates the number of thematic progression combinations in each chapter of the literary text.

Table 1. Thematic Progression in the literary text

\begin{tabular}{|c|c|c|c|c|c|}
\hline \multirow{2}{*}{ Chapter } & \multicolumn{3}{|c|}{ Types of Thematic Progression Combinations } & \multirow{2}{*}{ Total } & \multirow{2}{*}{} \\
& Linear-Constant & Elliptical & Constant-Linear & & \\
\hline & 4 & 7 & 2 & 13 & $8,1 \%$ \\
\hline 2 & 13 & 8 & 6 & 27 & $16,8 \%$ \\
\hline 3 & 9 & 5 & 4 & 18 & $11,2 \%$ \\
\hline 4 & 15 & 11 & 5 & 31 & $19,2 \%$ \\
\hline 5 & 11 & 9 & 8 & 28 & $17,4 \%$ \\
\hline 6 & 17 & 12 & 15 & 44 & $27,3 \%$ \\
\hline Total & 69 & 52 & 40 & 161 & 100 \\
\hline$\%$ & 42,9 & 32,3 & 24,8 & 100 & \\
\hline
\end{tabular}

The percentages indicate the use of linear-constant progression patterning $(42,9 \%)$ over other types. Elliptical thematic progression (32,3\%) type is also of important use here. The lower percentage is found in constant-linear thematic progression patterning where forty instances are found, with $24,8 \%$ of the total number of thematic progression combinations.

So, the linear-constant thematic progression predominates in the analysed literary text. However, other types (i.e., simple linear thematic progression and thematic progression with derived Themes) used fairly frequently facilitate coherent and cohesive relations within the text. As the research proves, linear-constant progression combinations predominate through all six chapters of the text; the sequence of thematic progression types make patterns. Constant-linear progression appears much more seldom, as elliptical progression prevails over it. The most regular pattern is the sequence of constant thematic progression and linear thematic progression types, moreover, the pattern of Thematic Progression in the literary genre arises from constant thematic progression intervened by linear thematic progression every 3-5 clauses. Derived thematic progression, used less frequently, also appears in almost every third paragraph. The preponderance of linear thematic progression over constant Theme patterns for a literary genre is also revealed by Abed (Abed, 2015).

The attention now should turn to the analysis of thematic progression patterns in each chapter of the selected legislative text (736 clauses selected from 161 articles). The types of its Thematic Progression are illustrated in the following examples. Examples 10-11 reveal the pattern of constant-linear thematic progression predominating in all articles of the text $(54,2 \%)$ :

(10) The Council shall adopt measures to ensure administrative cooperation between the relevant departments of the Member States in the areas covered by this Title, as well as between those departments and the Commission. It shall act on a Commission proposal, subject to Article 76, and after consulting the European Parliament (The Treaty on the Functioning of European Union, Article 74, 2008). 
T1 ( The Council) R1 (shall adopt measures to ...)

T1 (It) R2 (shall act on a Commission...).

(11) The Union shall endeavour to ensure a high level of security through measures to prevent and combat crime, racism and xenophobia, and through measures for coordination and cooperation between police and judicial authorities and other competent authorities, as well as through the mutual recognition of judgments in criminal matters and, if necessary, through the approximation of criminal laws. The Union shall facilitate access to justice, in particular through the principle of mutual recognition of judicial and extrajudicial decisions in civil matters (The Treaty on the Functioning of European Union, Article 67, 2008).

T1 (The Union) R1 (shall endeavour to ensure... )

T1 (The Union) R2 (shall facilitate access to ...).

Example 12 demonstrates elliptical progression $(24,7 \%)$ in the middle of the text between constant thematic progressions. In Example 13 elliptic progression is in the middle of the extract between constant progression and at the end:

(12) If a Member State does not fulfil the requirements under one or both of these criteria, the Commission shall prepare a report. The report of the Commission shall also take into account whether the government deficit exceeds government investment expenditure and take into account all other relevant factors, including the medium term economic and budgetary position of the Member State. The Commission may also prepare a report if, notwithstanding the fulfilment of the requirements under the criteria, it is of the opinion that there is a risk of an excessive deficit in a Member State (The Treaty on the Functioning of European Union, Article 126, 2008).

T1 (... the Commission) R1 (shall prepare a report)

$\mathrm{T} 1$ (The report of the Commission) R2 (shall also take into account ...)

T1 ("The report of the Commission") R3 ( take into account...)

$\mathrm{T} 2$ (The Commission) R4 (may also prepare a report ...).

(13) The Union shall establish an internal market. It shall work for the sustainable development of Europe based on balanced economic growth and price stability, a highly competitive social market economy, aiming at full employment and social progress, and a high level of protection and improvement of the quality of the environment. It shall promote scientific and technological advance. It shall combat social exclusion and discrimination, and shall promote social justice and protection,equality between women and men, solidarity between generations and protection of the rights of the child. $\underline{I}$ shall promote economic, social and territorial cohesion, and solidarity among Member States. It shall respect its rich cultural and linguistic diversity, and shall ensure that Europe's cultural heritage is safeguarded and enhanced (The Treaty on European Union, Article 3, 2008).

T1 (The Union) R1 (shall establish an internal market)

T1 ( It) R2 (shall work for the sustainable...)

T1 ( It) R3 (shall promote scientific...)

T1 ( It) R4 (shall combat social exclusion...)

T1 ( and "It") R5 (shall promote social justice...)

T1 ( It) R6 (shall promote economic...)

T1 ( It) R7 (shall respect its rich cultural...)

T1 ( and "It") R8 (shall ensure ...)

Example 14 illustrates simple linear thematic progression type $(21,1 \%)$, where the Rheme of the previous clause becomes the Theme of the following:

(14) The Union shall develop a common policy on asylum, subsidiary protection and temporary protection with a view to offering appropriate status to any third-country national requiring international protection and ensuring compliance with the principle of non-refoulement. This policy must be in accordance with the Geneva Convention of 28 July 1951 and the Protocol of 31 January 1967 relating to the status of refugees, and other relevant treaties (The Treaty on the Functioning of European Union, Article 78, 2008).

T1 (The Union) R1 (shall develop a common policy...)

T2 (This policy) R2 (must be in accordance with ...).

The following table indicates the number of thematic progression combinations in each chapter of the legislative text.

The percentage indicates that the use of constant-linear progression pattern $(54,2 \%)$ prevails over other types. Elliptical thematic progression $(24,7 \%)$ is also used. The lower percentage is found in linear-constant progression patterning $(21,1 \%)$. 
Table 2. Thematic Progression in the legislative text

\begin{tabular}{|l|l|l|l|l|l|l|}
\hline \multirow{2}{*}{ Parts } & Articles & \multicolumn{2}{|c|}{$\begin{array}{l}\text { Types of Thematic Progression } \\
\text { Combinations }\end{array}$} & \multirow{2}{*}{ Total } & \multirow{2}{*}{} \\
\cline { 3 - 6 } & & $\begin{array}{l}\text { Constant- } \\
\text { Linear }\end{array}$ & $\begin{array}{l}\text { Elliptical } \\
\text { Cinear- } \\
\text { Constant }\end{array}$ & & \\
\hline TREATY ON EUROPEAN UNION & $1 / 55$ & 109 & 33 & 32 & 174 & 26,4 \\
\hline $\begin{array}{l}\text { TREATY ON THE FUNCTIONING OF } \\
\text { THE EUROPEAN UNION }\end{array}$ & $1 / 106$ & 249 & 136 & 101 & 486 & 73,6 \\
\hline Total & & 358 & 163 & 139 & 660 & 100 \\
\hline$\%$ & & 54,2 & 24,7 & 21,1 & 100 & \\
\hline
\end{tabular}

Two types of Thematic Progression are typical of the legislative text. Constant thematic progression type is prevailing over linear thematic progression one. There are also patterns made of constant thematic progression, linear thematic progression and elliptical thematic progression types. Patterns with elliptical progression are used more often than the linear-constant pattern. The constant-linear patterning predominates through all 161 articles. The pattern of Thematic Progression in the legislative genre is based on constant thematic progression intervened by linear thematic progression and elliptical progression every 5-7 clauses.

\section{Conclusions}

Thus, the analysis of Thematic Progression from two different genres reveals some differences and similarities between them. Linear and constant patterns predominate in literary and legislative texts. However, a literary text has a variety of other patterns made of constant thematic progression, linear thematic progression, derived thematic progression and elliptical progression types.

The small percentage of split Rheme in fiction also contributes to the variety of thematic progression types compared to the legislative text. The latter is commonly based only on constant-linear thematic progression patterning and less frequently on elliptic progression, while in the literary genre linear-constant thematic progression patterning is dominant.

Constant and linear patterns are more widely applied. Since all literary and legislative texts are meant to provide information, they naturally centre round a single topic and discuss it from several perspectives making the content information explicit. Therefore writers of literary and legislative texts repeat the same or a similar Theme throughout the texts to maintain what they are about. Linear-constant patterning with Themes actually derived from the Rhemes of preceding clauses helps to unfold textual episodes successively, giving new information after the disclosed one. It makes the text more coherent and effective for perception.

Constant-linear thematic progression patterning where several Rhemes comment on a similar Theme contributes to informativeness, argumentativeness, and unambiguity of the legislative text, the detailed specification of the information given in it. Additionally, there is not much variety of thematic progression patterns in the legislative genre compared to the literary one. While the literary text contains different situations with descriptions of characters where derived thematic progression is used, the legislative genre of the legislative articles with rules which do not comprise different descriptive situations could not be filled of derived thematic progression and a split Rheme. The abovementioned proves that the choice of thematic progression patterns is stipulated by stylistic relevance and genre, as well as the pragmatic value of texts.

Our further research will focus on the procedure of highlighting correlations between Theme choice (textual, interpersonal, experiential Themes) and thematic progression patterns of literary and legislative texts. The contrastive analysis of such correlations and their consituents will help us to support the theory of Functional Sentence Perspective in general and reveal functional specificity of thematic progression patterns of English texts of different genres in particular.

\section{References:}

Abed, A. Q. (2015). Patterns of thematic progression in C. Dickens' A Tale of Two Cities. Journal of the Faculty of Arts, 92, 77-101. Retrieved December 12, 2017, from https://www.iasj.net/iasj?func=article\&aId=4585

Abdol, K. Al., \& Hamed, S. (2014). Information development in Arabic research articles abstract. International Journal of English and Education, 3 (1), 42-49. Retrieved August 8, 2018, from http://ijee.org/yahoo_site_admin/assets/docs/4.115210.pdf

Consolidated versions of the Treaty on European Union and the Treaty on the Functioning of the European Union (2008). Official Journal of the European Union, 51. Retrived September 1, 2018, from https://eur-lex.europa.eu/legalcontent/EN/TXT/?uri=CELEX:12008E074

Daneš, F. (1989). Functional sentence perspective and text connectedness. In M. E. Conte, J. Petöfi \& E. Sözer. (Eds.), Text and Discourse Connectedness: Proceedings of the Conference on Connexity and Coherence (pp. 23-31). Amsterdam: John Benjamins. 
Daneš, F., (1974). Functional sentence perspective and the organization of the text. In F.Daneš (Ed.), Papers on Functional Sentence Perspective (pp. 106-128). Prague: Academia.

Drápela, M. (2015). The FSP bibliography. In Martin Drápela (Ed.), A Bibliography of Functional Sentence Perspective 1956-2011 (pp. 33-186). Brno: Masaryk University.

Dubois, B. L. (1987). A reformulation of thematic progression typology. Text 7(2), 89-116. https://doi.org/10.1515/text.1.1987.7.2.89

Dušková, L. (2015). Czech approaches to information structure: theory and applications. In Martin Drápela (Ed.), A Bibliography of Functional Sentence Perspective 1956-2011 (pp. 9-32). Brno: Masaryk University.

Enkvist, N. E. (1974). Theme dynamics and style: and experiment. Studia Anglica Posnaniensia 5, 127-135. Retrieved April 22, 2019, from https://repozytorium.amu.edu.pl/bitstream/10593/10627/1/12_enkvist.pdf

Fang, D., \& Li, S. (2015). Thematic structure and its application to English Writing. In P. Shaw (Ed.), Proceedings of the 2015 International Conference on Education Reform and Modern Management (pp. 263-266). Hong Kong: Atlantis Press, Curran Associates Inc. https://doi.org/doi:10.2991/ermm-15.2015.69.

Fibras, J. (1992). Functional sentence perspective in written and spoken communication. Cambridge: Cambridge University Press. https://doi.org/10.1017/CBO9780511597817

Fitzelald, S. F. (1996). Tender is the night. New York: Charles Scribner's Sons.

Ghadessy, M. (1995). Thematic development and its relationship to registers and genres. In M. Ghadessy (Ed.), Thematic development in English text (pp. 129-126). London: Pinter.

Halliday, M. A. K. (1995). An introduction to functional grammar. London: Edward Arnold.

Halliday, M. A. K., \& Hasan, R. (1976). Cohesion in English. London \& New York: Longman.

Maton, K., Martin, J. R., \& Matrrugilio, E. (2016). LCT and systemic functional linguistics: Enacting complementary theories for explanatory power. In K. Maton, S. Hood \& S. Shay (Eds.), Knowledge-building: Educational studies in Legitimation Code Theory (pp. 3-78). London: Routledge.

Nwogu, K. \& Bloor, T. (1991). Thematic progression in professional and popular medical texts. In E. Ventola (Ed.), Functional and Systemic Linguistics: Approaches and Uses (pp. 369-384). Berlin: Mouton de Gruyter.

Rahmawati, R. V. \& Kurniawan, E. (2015). Thematic progression analysis in Indonesian EFL students' thesis abstracts. Indonesian EFL Journal, 1(1), 81-87. https://doi.org/10.25134/ieflj.v1i1.617

Tan, J. H., \& Sun, W. G. (2010). Enlightenment of progression patterns of theme and rheme in English teaching. Journal of Xuzhou Normal University. Philosophy and Social Sciences Edition, 36(1), 140-143. Retrieved September 2, 2018, from http://caod.oriprobe.com/articles/17824026/Enlightenment_of_Progression_Patterns_of_Theme_and_Rheme_in_English_Te.htm 